\title{
¿Y AHORA QUÉ PARA LAS ESCUELAS DE NEGOCIOS DEL MUNDO?
}

JAMES A. F. STONER

Escuela de Negocios Gabelli

Universidad de Fordham

Nueva York, Nueva York, EE. UU.

stoner@fordham.edu

\section{EL DESAFIO (“¿Entonces qué es?”)}

Nuestra especie se enfrenta al desafío mas grande de toda la historia: cómo transformar el sistema dominante actual de produccióndistribución-consumo de uno que esta destruyendo la capacidad del planeta de sostener a nuestra especie a uno que permita que nuestra especie y todas las otras puedan continuar existiendo y "prosperando por siempre" (usando las palabras de John Ehnfeld), "curar un mundo quebrantado" (usando las palabras del Reporte del Equipo de Trabajo sobre la Ecología Jesuita), y lograr "una ecología integral," "cuidar a los vulnerables," y "cuidar nuestro hogar compartido" (usando las palabras y el subtítulo de la encíclica Laudato Si' del Papa Francisco). Es evidente que el sistema en el que vivimos no funciona. Continuamente e incrementadamente está perjudicando todos los aspectos del ecosistema global, creando niveles nunca antes vistos de disparidad en los ingresos y riquezas alrededor del mundo, generando el cambio climático, calentamiento global, y cambios de clima inusuales que afectan a todo el planeta, dando pie a la sexta gran extinción.

El desafío al que se enfrenta nuestra especie puede parecer particularmente irreversible por la manera en la que producimos, distribuimos, y consumimos está incrustada en un mecanismo aparentemente bien integrado, bien reforzado, y poderoso que está tan bien articulado y anclado que es difícil imaginar una posible alternativa. Y aunque podamos imaginarnos muchas alternativas, los obstáculos para poder cambiar parecen ser tan numerosos e impenetrables que corremos 
el riesgo de des-empoderarnos y ni siquiera intentar generar cambios que pueden parecer atractivos y prometedores.

Aun así, mientras la naturaleza muy completa y firmemente interconectada del sistema global de producción-distribución-consumo representan un desafío que parece imposible, está claro que el sistema no puede continuar en su forma actual por mucho tiempo. La capacidad del planeta de sostener se está agotando rápidamente, y por ende debe cambiar. Entonces, la pregunta puede ser “¿Cómo y cuándo será cambiado?," aunque una mejor pregunta podría ser “¿Cómo podemos nosotros intervenir en el sistema para generar cambios en direcciones que son deseables para nuestra y otras especies?"

Desde su concepción, este Journal se ha preocupado por explorar cómo se puede procurar y crear un mundo más sostenible. Artículos anteriores, actuales y futuros han estando investigando y continuaran investigando maneras en las cuales ciertos aspectos de la sociedad pueden contribuir a las transformaciones necesarias de nuestros hábitos de produccióndistribución-consumo y maneras de estar en el mundo; en otras palabras, cómo podemos enfrentarnos al más grande desafío de nuestra especie. Esta edición del Journal no es la excepción; contiene un numero de artículos que tocan o se enfrentan a este desafío. Estos artículos son introducidos a continuación, después de un breve reportaje sobre una iniciativa que debemos acoger para combatir la transformación global.

\section{UNA RESPUESTA AL DESAFÍO (“¿Qué importa?”)}

Las buenas nuevas sobre este sistema monolítico, integrado y todo acaparador es que también parecen haber un numero infinito de lugares donde puede ser intervenido, lugares donde podría ser posible iniciar una trasformación positiva. Un lugar, el cual puede ser de gran interés para los lectores de esta revista, puede ser el área de la educación empresarial mundial, y un método en esta área que también puede ser interesante, es una iniciativa del 2016 de transformar la educación empresarial en un vehículo para cambiar el sistema global de producción-distribuciónconsumo, una iniciativa inspirada por el concurso de la Fundación MacArthur, 100\&Change.

El 2 de Junio del 2016, la Fundación MacArthur anunció un concurso de $\$ 100$ millones para resolver un problema social significante. El 10 de Julio, la posibilidad de entrar a este tipo de concurso-con una propuesta para transformar la educación empresarial en un vehículo para cambiar el sistema global de producción-distribución-consumo-fue brevemente 
discutida en el 19no Encuentro Anual de los Colegios de Educación Empresarial Jesuita (19th Annual Meeting of the Colleagues in Jesuit Business Education (CJBE)) en La Escuela Le Moyne en Syracuse, Nueva York. Ocho días después, en Nairobi, Kenia, la siguiente resolución fue aprobada de forma unánime en el Vigesimosegundo Foro Anual Mundial de la Asociación de las Facultades de Negocios Jesuitas (22nd Annual World Forum of the International Association of Jesuit Business Schools (IAJBS)):

El encuentro anual de la IAJBS solicita a la jefatura de IAJBS, la jefatura de CJBE, y el resto de la red de facultades de negocios jesuitas a trabajar juntos para aplicar a la concurso de 100 millones de dólares de la Fundación MacArthur, 100\&change con un proyecto para transformar la educación empresarial Jesuita para que esté completamente alineada con la sabiduría de Laudato Si', con nuestros principios educacionales Jesuitas universales, y con la necesidad de una sostenibilidad global, justicia social, y la reducción de la pobreza.

El 2 de Octubre del 2016, una propuesta de utilizar la red de facultades de negocios Jesuitas como un vehículo para transformar no solamente la educación empresarial Jesuita, pero toda la educación empresarial y el sistema mundial de producción-distribución-consumo fueron enviados la Fundación MacArthur. Desafortunadamente, no ganó el premio de 100 millones de dólares, pero su base estructural conceptual aún puede ser la semilla de una idea para transformar la educación empresarial y todo nuestro sistema de producción-distribución-consumo.

La propuesta del 2016 acepta que la educación empresarial global, en su mayoría, actualmente hace lo que se le pide: entrenar personas para que apoyen, contribuyan, y construyan sus carreras en el sistema existente de producción-distribución-consumo en el que todos vivimos. Pero ya que este sistema no funciona y no puede continuar su trayectoria actual, la propuesta admite que las enseñanzas e investigaciones empresariales actuales están contribuyendo al problema de la insostenibilidad en vez de proveer un liderazgo contundente para solucionarlo.

El método básico de la propuesta también aseguró que no hay un modelo único aceptado para reformar la educación e investigación empresarial y convertirla en un vehículo para transformar como producimos, distribuimos, y consumimos. Por ende, elaborando sobre la observación del profesor Hal Leavitt de que "cuando no sabes como resolver un problema, es una buena idea dárselo a un grupo," la aplicación propuso que los 100 millones de dólares fueran invertidos en 40 facultades de negocios, y cada cual se comprometería a transformar sus 
propios currículos en la manera que ellos quieran (o quizás descubran), y que lo hicieran en el periodo imposiblemente corto de tres años. Este periodo de tiempo fue escogido en parte por la urgencia del problema global de insostenibilidad y en parte también por la hipótesis que, en la academia y otras partes, lo que no se puede hacer en 20 años quizás sea posible en tres.

Es por eso, que el concepto de la propuesta no era entrenar a los estudiantes quienes, en 20, 30, o 40 años, llegarían a posiciones lo suficientemente altas en sus empresas $u$ otras organizaciones para poder iniciar las transformaciones necesarias en nuestro sistema productivodistributivo-consumo. En cambio, la intención era crear una conversación global inspirada por 40 facultades de negocios valientes buscando, y muy visiblemente lograr lo imposible, una conversación vocifera que generaría la atención inmediata de las empresas globales, instituciones educativas, gubernamentales, y sin animo de lucro en todo el mundo y, al hacer esto, iniciar la transformación de nuestro sistema de producción-distribuciónconsumo ahora mismo en vez de en las siguientes décadas.

\section{Y AHORA QUE PARA LAS FACULTADES DE NEGOCIOS DEL MUNDO (“¿Ahora qué?”)}

Lo que enseñamos e investigamos en las facultades de negocios puede ser el vehículo para influenciar y cambiar como el mundo produce, distribuye, y consume. Otro concurso de 100\&change está programado para el 2019 y otra propuesta similar a la enviada en el 2016 quizás sea postulada.

Aún falta mucho para el 2019, y el problema de insostenibilidad global parece empeorar cada año. Además, las enseñanzas e investigaciones de las facultades de negocios continúan apoyando, en su mayoría, nuestro paradigma actual de producción-distribución-consumo. Como tal, aunque pueda parecer deseable desarrollar una propuesta para aplicar a la Fundación MacArthur para cumplir con el mismo objetivo-la trasformación total del sistema de producción, distribución-consumotambién sería posible para las facultades de negocios tomar la iniciativa en actuar inmediatamente sin esperar hasta el 2020 para ver si se gana el concurso. Un punto de partida puede ser solo una facultad de negocios que esté dispuesta a admitir que nuestro sistema global no funciona, que la educación actual en las facultades de negocios contribuye al disfuncionalidad, y que eso mostrará el camino hacia una solución a la disfuncionalidad al transformar su propio currículo, quizás alineándose con la resolución de Nairobi, en el periodo de tiempo imposiblemente 
corto de tres años y haciéndolo de manera publica de tal manera que todo el mundo observe.

La cuestión es: ¿existe tal facultad de negocios en algún lado que esté dispuesta a comprometerse a hacer lo imposible en un periodo de tiempo imposiblemente corto ... y hay, quizás, otras facultades que encuentren inspiración de la primera escuela para hacer lo mismo?

\section{ESTA EDICIÓN DE LA REVISTA}

Ahora sobre los artículos de esta edición del Journal.

En el segundo de tres artículos previstos sobre la transformación de la educación empresarial en un vehículo para cambiar nuestro sistema de producción-distribución-consumo, Frank Werner y James Stoner se enfocan en el papel fundamental que tienen nuestras enseñanzas e investigaciones en las finanzas y como esto influencia todo el currículo de la facultad de negocios. En "Transformando la Educación Financiera y Empresarial: Las Oportunidades Únicas de las Finanzas," ellos sugieren que las finanzas tienen una oportunidad excepcional de ser protagonistas al transformar la totalidad del currículo empresarial. Además, mientras cada miembro de la facultad de finanzas y sus departamentos puede ser un líder al transformar toda la educación de finanzas y empresarial, ellos también describen porque la facultad de finanzas y departamentos en los colegios empresariales Jesuitas están bien posicionados para hacer esto.

En "Hacia una Teoría de las Artes y la Sostenibilidad," Nancy Bertaux y Kaleel Skeirik también hablan específicamente sobre las oportunidades para transformar nuestro sistema de producción-distribución-consumo y nuestra forma de estar en el mundo. Reconociendo la necesidad de construir "una base amplia de un consenso público para la acción" (p. 53) sobre los grandes cambios que demos lograr, ellos presentan un modelo teórico para el papel que pueden tener las artes en generar dicho consenso. En el centro de su perspectiva está su idea de que las artes quizás son únicas en su habilidad para hablar directo a nuestros corazones y almas, que la complejidad artística puede ser un vehículo para emparejar la complejidad de los desafíos y cambios que demos enfrentar, y que este emparejamiento puede inspirar la participación pública en los pasos que debemos tomar para lograr un mundo sostenible.

En "Visión y Practica en Sostenibilidad: La Aparente Brecha Entre lo que Dicen los Lideres Corporativos y las Percepciones de Estudiantes de MBA Polacos y Estadounidenses de Tres Universidades," Al Rosenbloom 
y Douglas Ross exploran un aspecto importante de la educación sobre la sostenibilidad que proveemos en nuestros programas de MBA. Ellos obtuvieron datos de tres grupos diferentes de estudiantes de MBA y los contrastaron con sus percepciones de la formación que estaban recibiendo con las habilidades y mentalidades que los lideres corporativos indicaron que les gustaría que sus empleados tuvieran. Mientras los estudiantes generalmente percibieron un "vinculo positivo entre las practicas de sostenibilidad y el rendimiento" (p. 75) de organizaciones empresariales, los hallazgos de los autores sugieren que hay tres brechas entre la percepción de los estudiantes y las necesidades aparentes de las empresas:

\begin{abstract}
Entre los estudiantes deseando un estudio más profundo sobre la sostenibilidad versus la falta de oportunidades que actualmente están disponibles en sus programas de MBA (brecha 1); entre los estudiantes deseando que los miembros de la facultad estén más involucrados y que estén completamente comprometidos a enseñarles temas de sostenibilidad versus las actuales experiencias en el salon de la facultad presentado problemas de sostenibilidad de manera "prefabricada" (brecha 2); y entre el conocimiento normativo de los estudiantes de que la sostenibilidad mejora el rendimiento corporativo versus su análisis de que sus programas de MBA no están desarrollando sus competencias en sostenibilidad al máximo, las cuales son necesarias para conectar los resultados del rendimiento con la sostenibilidad (brecha 3). (p. 92)
\end{abstract}

Ellos también observan que la brecha 3 "causa que la percepción de los estudiantes sea que están mal preparados para afrontar los obstáculos en el trabajo que impiden que la sostenibilidad se convierta en un asunto central y organizacional" (p. 92). Rosebloom y Ross entonces sugieren formas de cómo se pueden cerrar esas brechas.

En "Empresas Confesionales Socialmente Responsables: Casos Selectos de las Filipinas," Aliza Racelis se enfoca en el papel que juegan las organizaciones confesionales y pueden continuar jugando al contribuir en desarrollo de un mundo más sostenible. Ella nota que es particularmente notable el éxito de las empresas sociales confesionales "en efectuar cambio sostenible y holístico ... a causa de su arraigo (y conexión) con la comunidad (por ende, ser capaces de cerrar las brechas socioeconómicas), el capital social que ellos ayudan a producir, el respeto que ellos reciben de la gente," (p. 118) y un modelo integral de desarrollo y ambiental. Basado en una revisión de literatura sobre las empresas sociales confesionales y su estudio de tres empresas filipinas, ella identifica un conjunto de valores distintivo en tales organizaciones, sus maneras particulares de operación y gobernabilidad, y el lugar especial que tienen en sus comunidades y en la sociedad en general. Ella también 
provee un modelo para predecir su éxito y contribuciones a un mundo más sostenible sobre la base de dos factores clave: liderazgo espiritual y lo que ella denomina "capital social cristiano."

Por último, Marinilka Kimbro y Eric Wehrly conversan sobre una de las áreas principales de creación-sostenibilidad donde se necesita innovación, pensamiento transformativo, y métodos transformativos de análisis: decisiones de distribución de capital que involucran proyectos con alternativas sostenibles relacionadas a la sostenibilidad. En "Planificación Capital, Selección, e Inversión: Integrando la Sostenibilidad en la Toma de Decisiones," ellos detallan las áreas principales donde técnicas existentes de análisis de inversión de capitales y maneras de pensar no están analizando correctamente proyectos promisorios que aportan a la sostenibilidad y usualmente los ponen en desventaja. Los autores entonces van más allá de solo señalar las falencias de las técnicas y pensamientos analíticos actuales, dando sugerencias y procesos concretos para mejorar las decisiones de capital que pueden contribuir a un mundo más sostenible. Su articulo nos da un excelente ejemplo de los nuevos tipos de pensamientos que debemos traer a todo el proceso de transformar nuestro sistema de producción-distribución-consumo y la manera de estar en el mundo. 